\title{
Localization and Alternative Splicing of Agrin mRNA in Adult Rat Brain: Transcripts Encoding Isoforms that Aggregate Acetylcholine Receptors Are Not Restricted to Cholinergic Regions
}

\author{
Lawrence T. O'Connor, Julie C. Lauterborn, Christine M. Gall, and Martin A. Smith \\ Department of Anatomy and Neurobiology, University of California at Irvine, Irvine, California 92717
}

\begin{abstract}
Agrin is a protein implicated in the formation and maintenance of the neuromuscular junction. In addition to motor neurons, agrin mRNA has been detected in the brains of embryonic rat and chick and adult marine ray, suggesting that this molecule may also be involved in the formation of synapses between neurons. As a step toward understanding agrin's role in the CNS, we utilized Northern blot and in situ hybridization techniques to analyze the regional distribution and cellular localization of agrin mRNA in the spinal cord and brain of adult rats. The results of these studies indicate that the agrin mRNA is expressed predominantly by neurons broadly distributed throughout the adult CNS. Moreover, expression of agrin mRNA is not restricted to cholinergic structures or regions of the brain receiving cholinergic input. Recently, RNA isolated from rat embryonic spinal cord was shown to contain four alternatively spliced agrin mRNAs,

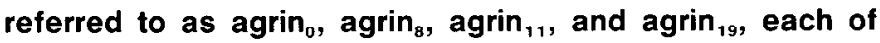
which encodes agrin proteins that are active in acetylcholine receptor aggregating assays (Ferns et al., 1992). Using the polymerase chain reaction we demonstrate that all four of these agrin transcripts are expressed within the adult CNS. Agrin $_{0}$, agrin $_{8}$, and agrin 19 were present in all regions analyzed. In contrast, agrin ${ }_{11}$ was detected only in forebrain. Results of these studies indicate that both the level of expression and pattern of alternative splicing of agrin mRNA are differentially regulated in the brain. The broad and predominantly neuronal distribution of agrin mRNA in the adult brain suggests that, in addition to its role at the neuromuscular junction, agrin may play a role in formation and maintenance of synapses between neurons in the CNS.

[Key words: agrin, synapse, ACh receptor, central nervous system, extracellular matrix, alternative RNA splicing, gene expression]
\end{abstract}

Identification of the mechanisms that underlie the formation of chemical synapses during development and their modification in the adult is of critical importance to understanding nervous system function. While the majority of synapses occur between neurons in the CNS, their heterogeneity and inaccessibility have hampered progress in characterizing the cellular interactions

\footnotetext{
Received March 24, 1993; revised July 16, 1993; accepted Aug. 9, 1993.

We thank Drs. S. Akbarion and D. O'Dowd for their critical reviews of the manuscript during its preparation. This work was supported by grants from the Plum Foundation (M.A.S.) and NIH Grants NS27563 (M.A.S.), NS26748 and RSDA MH00974 (C.M.G.). L.T.O. is a recipient of NIH Postdoctoral Training Fellowship NS07351.

Correspondence should be addressed to Martin A. Smith at the above address. Copyright (C) 1994 Society for Neuroscience $0270-6474 / 94 / 141141-12 \$ 05.00 / 0$
}

that direct their organization. In comparison, much more is known about the neuromuscular junction. Like other chemical synapses, the neuromuscular junction is characterized by specializations that adapt it for its role in synaptic transmission. In particular, the postsynaptic apparatus is associated with a high concentration of acetylcholine receptors (AChR). The accumulation of AChR is an early event in development of the neuromuscular junction and has been shown to be the result of inductive interactions between motor neurons and muscle fibers they innervate (reviewed in Hall and Sanes, 1993). Current evidence suggests that agrin, a synaptic basal lamina protein, mediates the motor neuron-induced accumulation of $\mathrm{AChR}$ at the developing neuromuscular synapse (reviewed in Nastuk and Fallon, 1993).

Interest in understanding the molecular mechanisms of agrin action and its role in synaptogenesis has led to the isolation of cDNA clones for agrin in several species, including electric ray (Smith et al., 1992), chicken (Tsim et al., 1992), and rat (Rupp et al., 1991). Analysis of its predicted amino acid sequence indicates that agrin is a large multidomain protein that can be divided into approximately two halves (for review, see Patthy and Nikolics, 1993). The amino-terminal portion of the protein contains nine modules related to follistatin and a region similar to the extracellular matrix protein laminin. The carboxy-terminal half of agrin is characterized by additional laminin-like domains and four regions similar to repeated structures found in epidermal growth factor. Expression studies have shown that all of the structural elements required for inducing aggregation of AChR on cultured myotubes are present within the carboxyterminal half of the protein (Ruegg et al., 1992; Tsim et al., 1992). In addition, alternative splicing events within this portion of the protein have been implicated in regulating agrin's AChR clustering activity (Ferns et al., 1992; Ruegg et al., 1992; Tsim et al., 1992). Functions associated with agrin's aminoterminal domains, however, remain to be determined.

Consistent with its proposed role in neuromuscular synapse formation, agrin mRNA is expressed in embryonic spinal motor neurons at a time when neuromuscular synapses are first forming (Rupp et al., 1991; Tsim et al., 1992). However, expression of agrin is not restricted to spinal motor neurons. Agrin mRNA has been detected by Northern blot analysis in the brains of embryonic rats and chickens (Rupp et al., 1991; Tsim et al., 1992) and in the brains of adult electric rays (Smith et al., 1992). These findings raise the possibility that agrin may also direct formation of the postsynaptic apparatus of neuronal synapses in the CNS. However, alternate roles for agrin, based on its structural similarity to components of the extracellular matrix that are known to influence aspects of neuronal growth and 


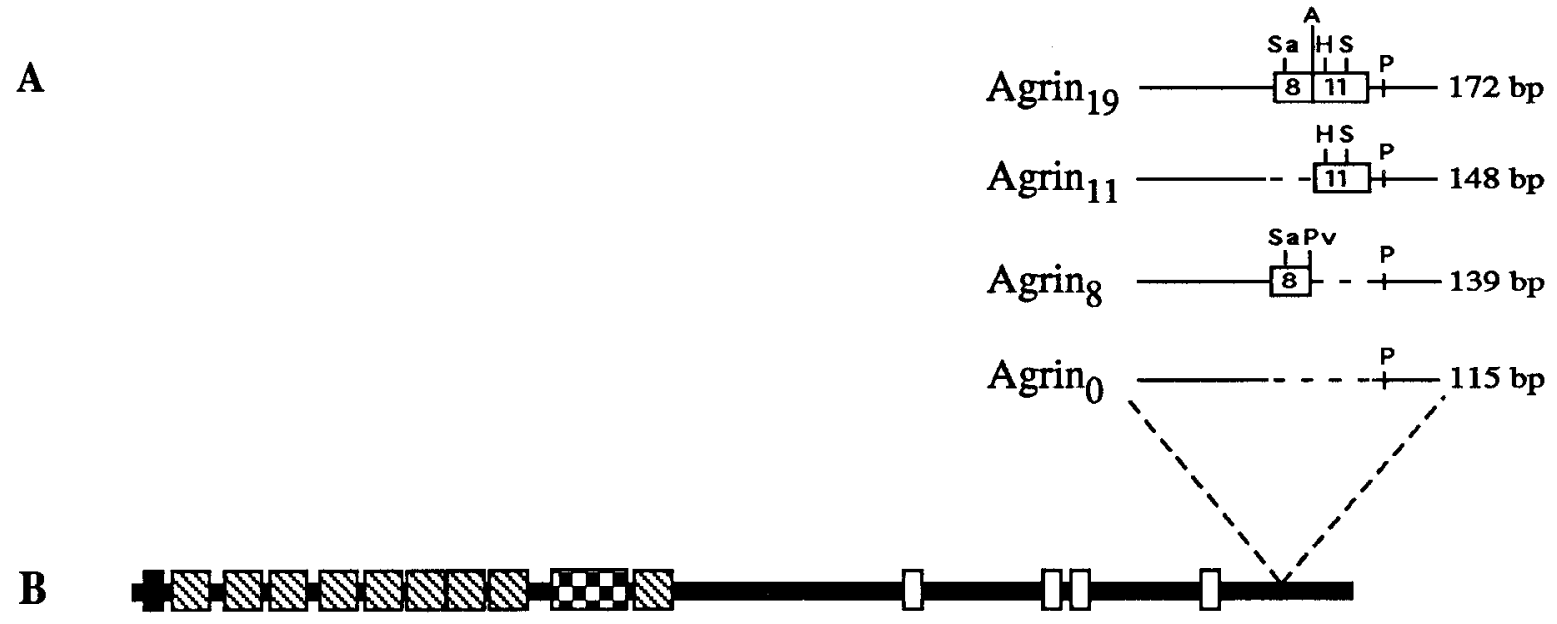

C

(a)

(b)

(c)

(d)

(e)

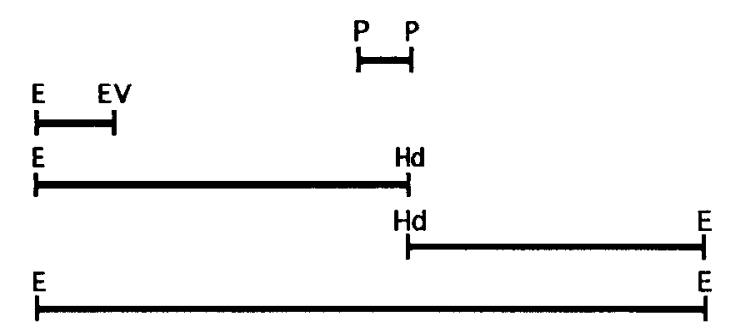

AAA

Figure 1. Schematic of the rat agrin cDNA showing the restriction map used to verify the identity of PCR products amplified from alternatively spliced agrin mRNAs $(A)$, agrin's predicted structural domains $(B)$, and the locations of restriction fragments used as probes in the study $(C)$. $A$, PCR amplification of rat brain RNA using nested primers flanking amino acid 1779 identified four alternatively spliced agrin mRNAs. The identity of these products was confirmed by restriction digests using the indicated enzymes. $B$, Structural domains predicted from the rat agrin amino acid sequence include a hydrophobic region (solid) follistatin-related modules (hatched), a laminin-like region (checkered), and epidermal growth factor repcats (open). C, Restriction fragments used as probes were derived from the 3'-half of the rat agrin cDN $\Lambda$. $a$, a $0.25 \mathrm{~kb}$ Pstl fragment (corresponding to nucleotides 5626-5876); $b$, a $0.38 \mathrm{~kb}$ EcoR 1-EcoRV fragment (nucleotides 4070-4446); $c$, a $1.8 \mathrm{~kb}$ EcoR 1-HindIII fragment (nucleotides 40705879 ); $d$, a $1.4 \mathrm{~kb}$ HindIII-EcoR 1 fragment (nucleotides 5879-7286); and $e$, a $3.2 \mathrm{~kb}$ EcoR 1 fragment (nucleotides 4070-7286). Northern blot andlysis was performed using both the 1.8 and $3.2 \mathrm{~kb}$ fragments. In situ hybridization studies utilized the $3.2 \mathrm{~kb}$ fragment as a template for cRNA probe synthesis; however, similar results were also obtained in a limited number of experiments using probes derived from the 1.8, $1.4,0.38$, and $0.25 \mathrm{~kb}$ fragments. Abbreviations include $A$ (AlwNI), $E$ (EcoRI), $E V$ (EcoRV), $H d$ (HindIII), $I$ (HinfI) $P$ (Pst1), $P$ v (PvuII), $S a$ (Sau3AI), $S$ (SmaI).

differentiation (reviewed in Reichardt and Tomaselli, 1991), seem equally likely. Nonetheless, localization of agrin mRNA in brain suggests a role for agrin in the nervous system beyond that originally proposed at the neuromuscular junction.

As a first step toward understanding agrin's wider role, we have begun a detailed analysis of agrin mRNA expression in the adult rat CNS. Using Northern blot, in situ hybridization, and polymerase chain reaction (PCR) techniques we have examined the distribution and pattern of alternative splicing of agrin mRNA in the adult rat CNS. Since agrin is implicated in the organization of the neuromuscular junction, a nicotinic cholinergic synapse, we also compared the pattern of agrin expression with the distribution of cholinergic and nicotinic cholinoceptive neurons in the brain.

\section{Materials and Methods}

Northern blot analysis. Adult Sprague-Dawley rats were killed by decapitation. Brains and spinal cords were then dissected free, frozen in liquid nitrogen, and stored at $-70^{\circ} \mathrm{C}$. RNA was isolated from frozen tissue by acid guanidinium thiocyanate-phenol-chloroform extraction (Chomczynski and Sacchi, 1987). Twenty micrograms of each RNA sample were fractionated by electrophoresis through a $1.2 \%$ agarose, $2.2 \mathrm{M}$ formaldehyde gel (Sambrook et al., 1989) and transferred to a Zeta-Probe nylon membrane (Bio-Rad, Richmond, CA). Membranes were hybridized according to the manufacturer's instructions for 18-24 $\mathrm{hr}$ with approximately $10^{6} \mathrm{cpm} / \mathrm{ml}$ of a ${ }^{32} \mathrm{P}$-labeled probe, synthesized by random primer extension (Feinberg and Vogelstein, 1983) from either a 1.8 or 3.2 kilo base $(\mathrm{kb})$ restriction fragment (Fig. 1) of a rat agrin cDNA (generously supplied by F. Rupp and R. Scheller, Dept. of Molecular and Cellular Physiology, Stanford University). After a final high-stringency wash at $65^{\circ} \mathrm{C}$ for $45 \mathrm{~min}$ in $20 \mathrm{mM} \mathrm{Na}_{2} \mathrm{HPO}_{4}$, pH 7.2 , containing $1 \%$ SDS, membranes were exposed to X-OMAT film (Eastman-Kodak, Rochester, NY) for $1-7 \mathrm{~d}$ at $-70^{\circ} \mathrm{C}$ with an intensifying screen. Membranes were subsequently stripped of the agrin probe and hybridized a second time with a ${ }^{32} \mathrm{P}$-labeled probe synthesized from a $0.68 \mathrm{~kb}$ BamHI-PstI fragment of the rat cyclophilin cDNA clone pIBI5 (Milner and Sutcliff, 1983). Quantitative densitometry of film autoradiograms was performed using a MicroComputer Image Device (Imaging Research Inc., Ontario, Canada).

In situ hybridization. Adult Sprague-Dawley rats were given a lethal injection of sodium pentobarbital and perfused transcardially with a $4 \%$ paraformaldehyde solution in $0.1 \mathrm{M}$ phosphate buffer, $\mathrm{pH} 7.2$. Brains and spinal cords were removed and postfixed in the perfusate overnight at $4^{\circ} \mathrm{C}$, transferred to $4 \%$ paraformaldehyde in phosphate buffer containing $20 \%$ sucrose for $48 \mathrm{hr}$, and stored at $-70^{\circ} \mathrm{C}$. Tissues were sectioned at a thickness of $25 \mu \mathrm{m}$ in either a coronal or sagittal plane on a freezing microtome. Tissue sections were then processed for in situ hybridization in order to localize agrin mRNA. In preliminary studies designed to optimize conditions for in situ hybridization, tissue sections of adult rat brain were hybridized to cRNA probes derived from five restriction fragments (Fig. 1) of the rat agrin cDNA (Rupp et al., 1991) that had been subcloned into pBluescript II KS- (Stratagene, La Jolla, 
CA). Riboprobes were transcribed from linearized plasmids using either T7 or T3 RNA polymerase in the presence of ${ }^{35}$ S-UTP. Based on the results of these experiments, a $3.2 \mathrm{~kb}$ cRNA probe was determined to give the highest signal-to-noise ratio and was therefore used in the majority of in situ hybridization studies. However, all probes exhibited an identical pattern of regional and cellular hybridization.

Hybridization and washing conditions used in this study were identical to those previously described (Gall and Isackson, 1989; Lauterborn et al., 1991). In some experiments, alternate sections were processed for in situ hybridization using ${ }^{35} \mathrm{~S}$-labeled cRNA probes to localize mRNAs encoding either choline acetyltransferase (ChAT) (Lauterborn et al., 1993) or the $\beta 2$ subunit of the nicotinic AChR (Deneris et al., 1988). Tissue sections were mounted on gelatin-coated slides following in situ hybridization, air dried, and exposed to $\beta$-Max hyperfilm (Amersham, Arlington Heights, IL) for $2-4$ d. Mounted sections were subsequently defatted with chloroform, dipped in Kodak NTB2 emulsion (Eastman-Kodak, Rochester, NY), and exposed for 3-6 weeks at $4^{\circ} \mathrm{C}$. Following autoradiographic development, sections were stained with cresyl violet and coverslipped in Permount (Fisher Scientific, Tustin, CA). Some sections were also stained with toluidine blue, which enabled better visualization of neuronal cell bodies in tissue sections processed for in situ hybridization.

Controls for specificity of hybridization included either hybridizing alternate sections with a ${ }^{35} \mathrm{~S}$-labeled cRNA sense riboprobe or treating sections with $50 \mu \mathrm{g} / \mathrm{ml}$ of RNase A and $20 \mu \mathrm{g} / \mathrm{ml}$ of RNase T1 prior to hybridization with an antisense riboprobe. In both cases, no cellular labeling of tissue was evident.

PCR analysis. Alternatively spliced agrin mRNAs (Fig. 1) were identified by PCR amplification of RNA isolated from various regions of the CNS using nested primers flanking amino acid 1779 of the rat agrin cDNA (Rupp et al., 1991). First-strand cDNA was synthesized using Moloney's murine leukemia virus reverse transcriptase (GIBCO-Bethesda Research Labs, Gaithersburg, MD) and random hexanucleotide primers (Pharmacia, Piscataway, NJ) as previously described (Kawasaki, 1990). cDNA equivalent to $100 \mathrm{ng}$ of total RNA was amplified in a buffer containing $50 \mathrm{~mm} \mathrm{KCl}, 10 \mathrm{~mm}$ Tris- $\mathrm{HCl}, \mathrm{pH} 9,1.5 \mathrm{~mm} \mathrm{MgCl}_{2}$, $0.2 \mathrm{~mm}$ dNTPs, $20 \mathrm{pmol}$ of each primer, and $2.5 \mathrm{U}$ of Taq polymerase in a final volume of $100 \mu \mathrm{l}$. For the first round of amplification, a forward primer corresponding to nucleotides 5323-5344 and a reverse primer complementary to nucleotides 5712-5734 of the rat agrin cDNA were used. DNA was amplified in a thermal cycler (Perkin Elmer, Norwalk, CT) for 35 cycles $\left(94^{\circ} \mathrm{C}\right.$ for $1 \mathrm{~min}, 59^{\circ} \mathrm{C}$ for $2 \mathrm{~min}, 72^{\circ} \mathrm{C}$ for $3 \mathrm{~min}$ ) followed by a final extension at $72^{\circ} \mathrm{C}$ for $10 \mathrm{~min}$. An aliquot of the amplification mixture was subsquently diluted 1000 -fold and reamplified using a forward primer corresponding to nucleotides 5462-5485 and reverse primer complementary to nucleotides 5553-5576 of the rat agrin cDNA. Reaction conditions for the second round of amplification were identical to those described for the first, except that primer annealing was performed at $54^{\circ} \mathrm{C}$ and PCR products were labeled by inclusion of $2 \times 10^{5} \mathrm{cpm}$ of the forward primer end-labeled with ${ }^{32} \mathrm{P}$ using T4 kinase (Sambrook et al., 1989). PCR products were separated by electrophoresis on an $8 \%$ polyacrylamide gel and visualized by autoradiography. Autoradiograms were analyzed by quantitative densitometry using a MicroComputer Image Device (Imaging Research Inc., Ontario, Canada). The identity of each PCR product was confirmed by restriction analysis (Fig. 1). As a preliminary test, fragments were digested with PstI, an enzyme whose recognition sequence is predicted in all four PCR products. Subsequently, agrin $_{8}$ was identified by two unique restriction sites, Sau3AI and PvuII, one of which (PvuII) lies in the 3 boundary with agrin $_{0}$. Agrin ${ }_{11}$ was also identified by two unique restriction sites, Hinfl and SmaI. Finally, agrin ${ }_{19}$ was identified by an AlwNI site, formed at the junction of agrin $_{8}$ and agrin ${ }_{11}$, and by the presence of Sau3AI, HinfI and SmaI but not PvuII.

\section{Results}

\section{Northern blot analysis of agrin $m R N A$}

To examine the regional distribution and levels of expression of agrin mRNA in the adult rat CNS, total RNA was isolated from spinal cord and different brain regions and examined by Northern blot analysis using a ${ }^{32} \mathrm{P}$-labeled cDNA probe corresponding to $1.8 \mathrm{~kb}$ fragment of the rat agrin cDNA (Fig. 1). Previous studies have shown that a single $8.2 \mathrm{~kb}$ agrin mRNA is expressed in embryonic rat spinal cord and whole brain (Rupp

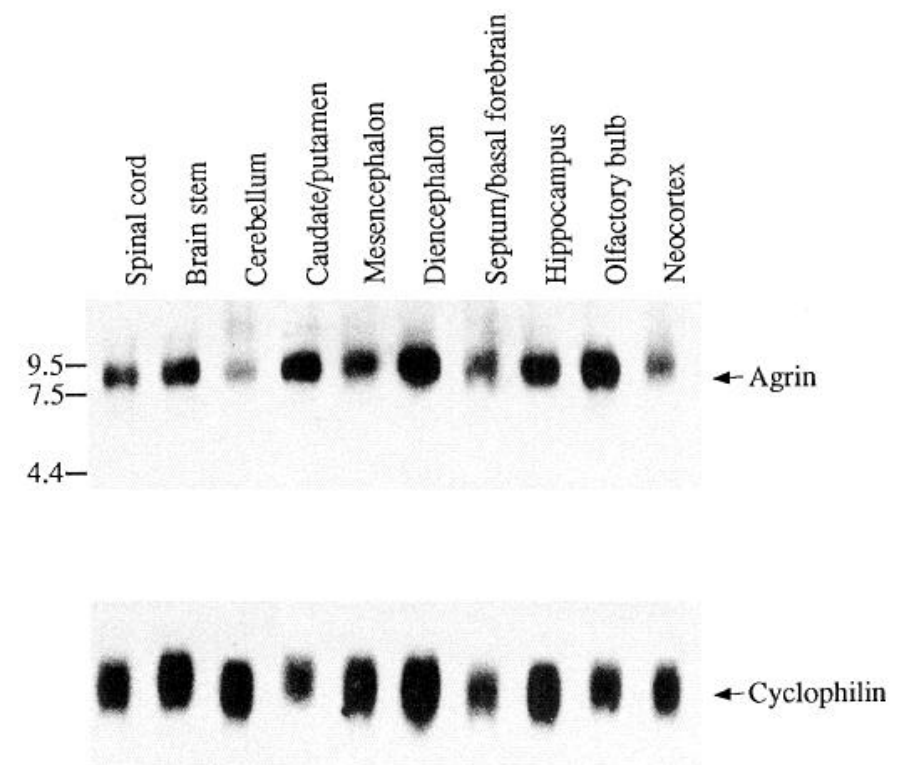

Figure 2. Agrin mRNA expression in the adult rat CNS: film autoradiograms of a Northern blot hybridized with a ${ }^{32} \mathrm{P}$-labeled agrin probe and subsequently stripped and reprobed for cyclophilin mRNA. Each lane contains $20 \mu \mathrm{g}$ of total RNA isolated from the indicated region of adult rat CNS. A single $8.2 \mathrm{~kb}$ agrin transcript is present in RNA from spinal cord and all other regions analyzed. Numbers indicate the positions of RNA molecular weight standards (in $\mathrm{kb}$ ).

et al., 1991). Consistent with these observations, a single transcript of approximately $8.2 \mathrm{~kb}$ was recognized in RNA isolated from adult spinal cord and all regions of the brain analyzed (Fig. 2). Similar results were also obtained with a second probe corresponding to the $3.2 \mathrm{~kb}$ agrin cDNA that was used to generate cRNA probes for in situ hybridization studies described below (data not shown).

Differences in the relative intensities of the hybridization signal were apparent in these blots, suggesting that different brain regions express distinct levels of agrin mRNA. For example, hybridization to the $8.2 \mathrm{~kb}$ transcript was particularly intense for RNA samples from the diencephalon and olfactory bulb but relatively weak for samples from the cerebellum. Differences in hybridization levels did not result from variation in RNA loading, since levels of hybridization with a ${ }^{32} \mathrm{P}$-labeled cDNA probe for cyclophilin, whose mRNA is expressed at high abundance throughout the CNS (Danielson et al., 1988), were similar across all brain regions and spinal cord (Fig. 2). To compare more accurately the relative levels of agrin mRNA expression in different brain regions, autoradiograms of Northern blots from two independent RNA isolates were analyzed by densitometry. When normalized to spinal cord, agrin mRNA levels in the brain were highest in olfactory bulb and diencephalon, intermediate in brainstem, mesencephalon, hippocampus, neocortex, caudate/ putamen, and septum/basal forebrain, and lowest in cerebellum.

\section{Regional localization of agrin $m R N A$}

The Northern blots demonstrated that agrin mRNA is widely distributed in the adult rat CNS. To determine the cellular localization of transcripts, tissue sections through brain and cervical spinal cord were processed for in situ hybridization using an ${ }^{35} \mathrm{~S}$-labeled agrin cRNA probe synthesized from the $3.2 \mathrm{~kb}$ cDNA (Fig. 1). The distribution of hybridization was evaluated 

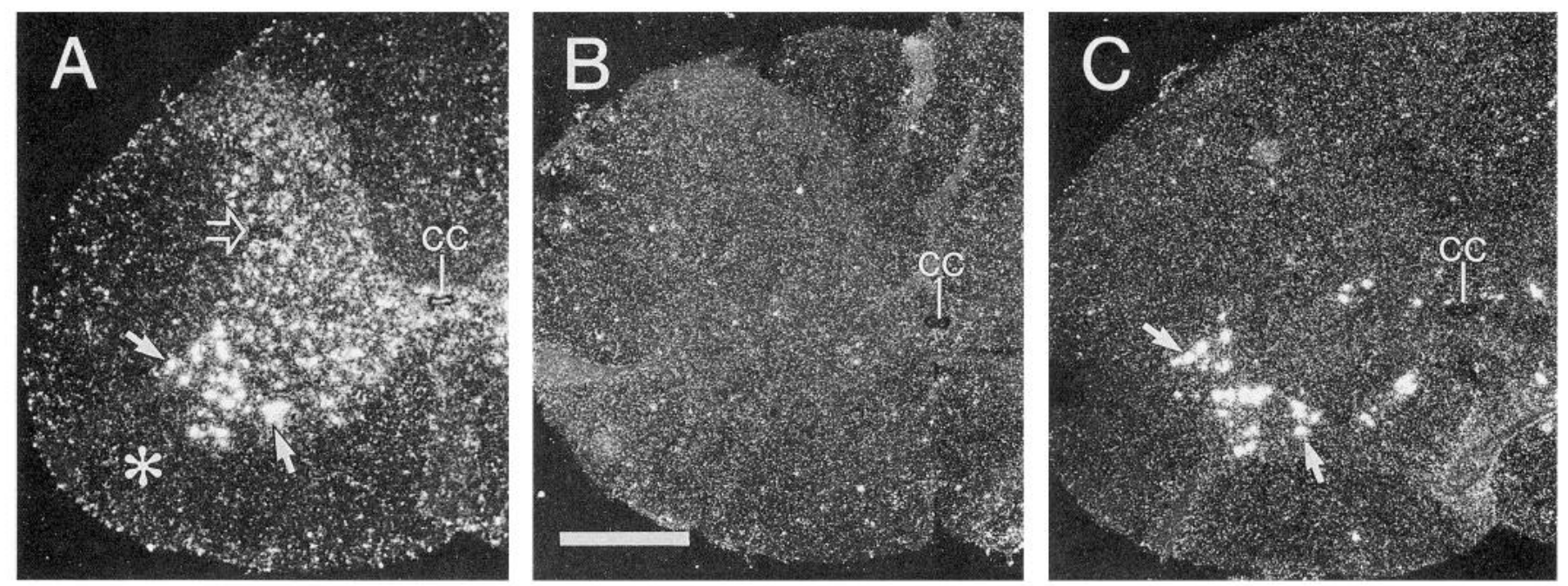

Figure 3. Agrin mRNA is present in adult rat spinal motor neurons: dark-field photomicrographs of transverse sections through cervical spinal cord of the adult rat hybridized with antisense $(A)$ and sense $(B){ }^{35} \mathrm{~S}$-labeled agrin cRNA probes or antisense ChAT cRNA probe $(C)$. The antisense agrin probe labeled large cell bodies in the ventral horn (solid arrows) which correspond to the distribution of ChAT mRNA containing motor neurons (solid arrows). Lower levels of hybridization are seen throughout the remaining gray matter (open arrow). Labeling of white matter (asterisk) by the antisense agrin probe was similar to the level of nonspecific labeling observed with the sense control probe. $c c$, central canal. Scale bar, $500 \mu \mathrm{m}$.

by both film and emulsion autoradiography (Figs. 3-5). Similar results (data not shown) were also obtained in other experiments using shorter cRNA probes derived from restriction fragments $(0.25 \mathrm{~kb}, 0.38 \mathrm{~kb}, 1.4 \mathrm{~kb}$, and the $1.8 \mathrm{~kb}$ cDNA used as a probe in the Northern blots) of the $3.2 \mathrm{~kb}$ template.

Previous studies have shown that agrin mRNA is expressed at high levels in spinal motor neurons (Rupp et al., 1991; Smith et al., 1992; Tsim et al., 1992). In agreement with these findings, dense accumulations of autoradiographic grains were observed over large neuronal cell bodies located in the ventral horn of the spinal cord with lower levels of specific labeling associated with neurons distributed throughout the remaining gray matter (Fig. $3 A$ ). Levels of labeling in the surrounding white matter were similar to the low levels of nonspecific hybridization observed in adjacent sections hybridized to the control sense cRNA probe (Fig. $3 B$ ). Adjacent sections were also processed for in situ hybridization to mRNA encoding ChAT, an enzyme in the synthetic pathway for ACh that serves as a marker for cholinergic neurons (Fig. $3 C$ ). The distribution of large neurons in the ventral horn containing ChAT mRNA corresponded to the distribution of cells labeled most intensely for agrin mRNA. Thus, based on the results of Northern blots and the cellular distribution of hybridization in the spinal cord, we concluded that the probes were specific for agrin mRNA and could be used, therefore, to examine the neuroanatomical distribution of agrin gene expression in the the adult rat nervous system.

Hybridization to agrin mRNA was broadly distributed throughout the brain. The autoradiographic localization of hybridization is shown in a rostral-to-caudal series of tissue sections through adult rat forebrain (Fig. 4) and hindbrain (Fig. 5). A brief summary describing the pattern of hybridization is presented in the following paragraphs.

\section{Telencephalon}

The olfactory bulb contained some of the most intensely labeled structures in rat brain (Fig. 4A). Hybridization was associated with cells in all principal neuronal layers, with labeling being greatest overlying the densely packed neurons of the internal granule cell layer. In addition, the olfactory nerve layer was very heavily labeled. In this region dense accumulations of autoradiographic grains labeled relatively small Nissl-dark cell bodies. The low level of nonspecific labeling seen in a section of olfactory bulb hybridized to the sense agrin cRNA probe (Fig. $4 B$ ) was typical of that observed throughout the brain.

Relatively dense labeling was observed in more caudal olfactory forebrain structures including the anterior olfactory nucleus (Fig. $4 A$ ), the tenia tecta (Fig. $4 C$ ), and the superficial cell layer of the olfactory tubercle (Fig. $4 D$ ), while the sparsely distributed neurons of the deeper ventral pallidum were more moderately labeled (not shown). In contrast, the densely packed neuronal clusters of the islands of Calleja were not labeled (Fig. 4D). Heavy labeling was also evident within the superficial layers of the piriform (Fig. $4 C$ ), cingulate (Fig. $4 C$ ), retrosplenial (Fig. $4 E$ ), and entorhinal (not shown) cortices. In neocortex, the agrin cRNA labeled cells in all neuronal layers while only background levels of autoradiographic grains were seen in layer I (Fig. $4 D$ ). Among neocortical layers, hybridization was greatest in layers II-IV and VI, with comparatively lower levels of hybridization evident in layer $\mathrm{V}$.

Moderate labeling was observed throughout the septum (Fig. $4 D$ ), amygdaloid complex (Fig. $4 E$ ), and globus pallidus (not shown). Moderate labeling was also evident in the caudate/ putamen, although specific hybridization was not detected in the traversing fiber bundles of the internal capsule (Fig. 4D). Within hippocampus, hybridization densely labeled cells in both the granule and pyramidal cell layers as well as in the hilus (Fig. $4 E$ ). In contrast, labeling in the CA 2 region was not significantly above background.

\section{Diencephalon}

Hybridization was broadly distributed across the diencephalon with comparatively greater labeling densities in medial hypothalamus (Fig. $4 E$ ) and intralaminar thalamic nuclei, including the central medial nucleus (Fig. $4 E$ ), the parafascicular nucleus (Fig. $4 F$ ), and the ventral lateral geniculate nucleus (Fig. $4 F$ ). Lower levels of hybridization were associated with the other thalamic relay nuclei. Moderately dense labeling was observed 

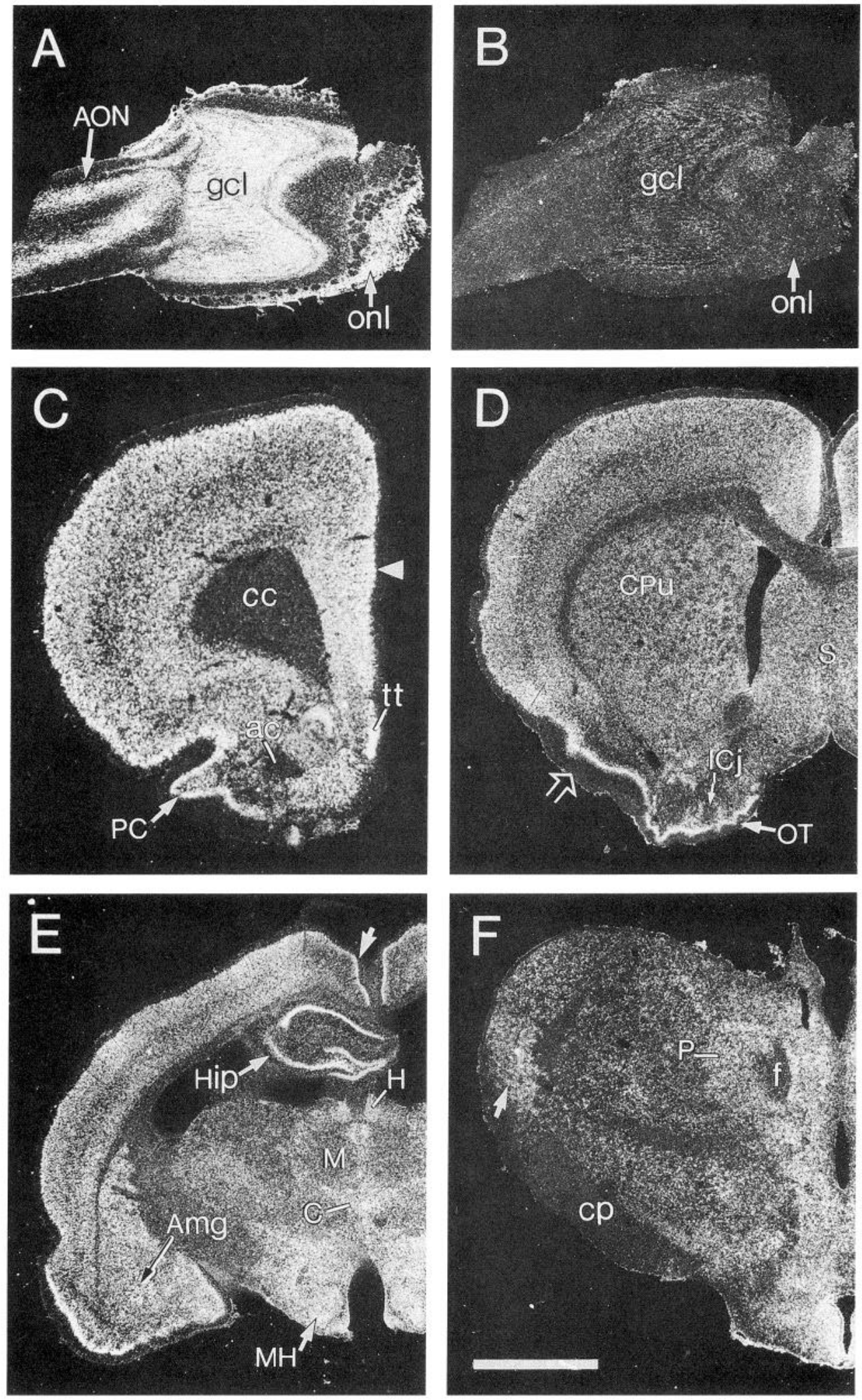

Figure 4. Agrin mRNA is expressed throughout the adult rat forebrain: darkfield low-magnification photomicrographs showing in situ hybridization of agrin antisense $(A, C-F)$ and sense $(B)$ ${ }^{35} \mathrm{~S}$-cRNA probes in a rostral to caudal series of sagittal $(A, B)$ and coronal $(C$ $F$ ) tissue sections through the telencephalon and diencephalon. Labeling of the olfactory bulb $(A)$ is very dense, particularly within the olfactory nerve $(o n l)$ and internal granule cell layers $(\mathrm{gcl})$, and more caudally within the anterior olfactory nucleus $(A O N)$. In contrast, very low levels of labeling are observed in similar sections hybridized with a sense probe $(B)$. In the forebrain $(C-E)$, highest levels of hybridization occur in piriform cortex $(P C)$, tinea tecta $(t t)$, olfactory tubercle $(O T)$, habenula $(H)$, amygdala $(A m g)$, and the principal cell layers of hippocampus (Hip), whereas lower levels of hybridization are visible in the superficial and deep layers of neocortex, superficial layers of cingulate cortex (arrowhead in $C$ ), retrosplenial cortex (arrow in E), caudate/ putamen $(C P u)$, and septum $(S)$. Only background levels of hybridization are seen within the major fiber tracts in these sections, including the anterior commissure $(a c)$, corpus callosum $(c c)$, layer I of piriform cortex (open arrow in D), the cerebral peduncle $(c p)$, and the fasciculus retroflexus $(f)$. Within the diencephalon $(E, F)$, dense hybridization labels the midline nuclei of the thalamus (e.g., $C$ ) and hypothalamus (e.g., $M H$ ) while lower levels were evident within the ventral lateral geniculate $(\mathrm{ar}$ row in $F$ ). $I C j$, islands of Calleja; $C$, central medial thalamic nuclei; $M$, mediodorsal nucleus; $M H$, medial hypothalamus; $P$, parafascicular nucleus. Scale bar: $2.1 \mathrm{~mm}$ for $A, 2.0 \mathrm{~mm}$ for $B$, $1.9 \mathrm{~mm}$ for $C, 2.2 \mathrm{~mm}$ for $D, 3.2 \mathrm{~mm}$ for $E, 1.4 \mathrm{~mm}$ for $F$

over cells located in the medial habenula, with somewhat lower levels evident over cells in the lateral habenula (Fig. 4E).

\section{Brainstem and cerebellum}

From rostral to caudal levels of the mesencephalon, the distribution of hybridization became less broadly distributed. In sec- tions through the superior colliculus, labeled cells were distributed across gray matter regions, with particularly heavily labeled cells evident in the deeper layers of superior colliculus and in the periaqueductal gray (not shown). In contrast, in more caudal sections, hybridization was very low in the central nucleus of the inferior colliculus and the pontine nuclei but was still dense 

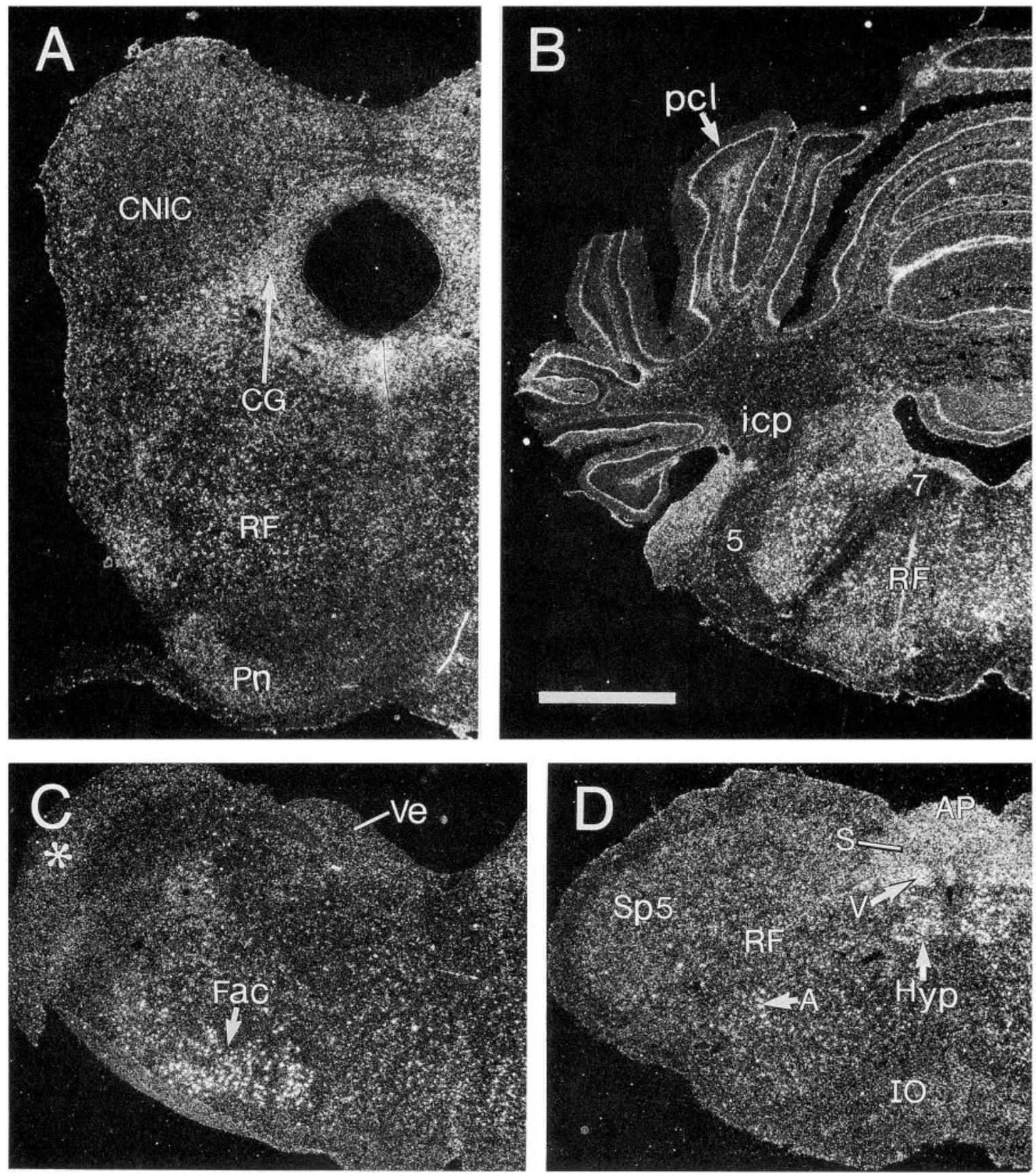

Figure 5. Distribution of agrin mRNA in the adult rat hindbrain: dark-field low-magnification photomicrographs showing in situ hybridization of agrin antisense ${ }^{35} \mathrm{~S}$-cRNA probes in a rostral $(A)$ to caudal $(D)$ series of coronal tissue sections through the mesencephalon and brainstem. In the mesencephalon $(A)$, cellular labeling is most prominent within the central periaqueductal gray region $(C G)$ while much lower levels of hybridization label neurons located in the central nucleus of the inferior colliculus $(C N I C)$, the pontine nuclei $(P n)$, and the reticular formation $(R F)$. In hindbrain $(B-D)$, highest levels of hybridization are observed in the Purkinje cell layer of the cerebellum ( $p c l)$, area postrema $(A P)$, and the motor cranial nerve nuclei including the facial $(\mathrm{Fac})$, vagus $(\mathrm{V})$, solitarius $(\mathrm{S})$, ambiguus $(\mathrm{A})$, and hypoglossal ( $\mathrm{Hyp}$ ). Lower levels of hybridization are apparent in the reticular formation $(R F)$, cochlear nuclei (asterisk), vestibular nuclei $(V e)$, spinal trigeminal nuclei $(S p 5)$, and inferior olive $(I O)$ ). Only background levels of hybridization are seen within the major fiber tracts in these sections including the spinal trigeminal tract (5), the facial nerve (7), and the inferior cerebellar peduncle (icp). Scale bar: $2 \mathrm{~mm}$ for $A, 1.6 \mathrm{~mm}$ for $B, 1.2 \mathrm{~mm}$ for $C, 1 \mathrm{~mm}$ for $D$.

in the central gray and in association with scattered cells in the pontine reticular formation (Fig. 5A). Only low levels of hybridization were evident in mesencephalic regions of cholinergic neurons, including the laterodorsal tegmental nucleus, the oculomotor nuclear complex, and the trochlear nucleus (not shown).

Within the cerebellum, the Purkinje cell layer (Fig. $5 B$ ) was prominently labeled as were scattered neurons in the deep cer- ebellar nuclei. Within the brainstem there are several efferent cranial nerve nuclei that contain peripherally projecting cholinergic neurons, including the motor nucleus of the trigeminal nerve (not shown), facial motor nucleus (Fig. 5C), hypoglossal nucleus (Fig. $5 D$ ), dorsal motor nucleus of the vagus (Fig. $5 D$ ), and the nucleus ambiguus (Fig. 5D). Neurons in all of these nuclei were densely labeled with the agrin cRNA. The nucleus 

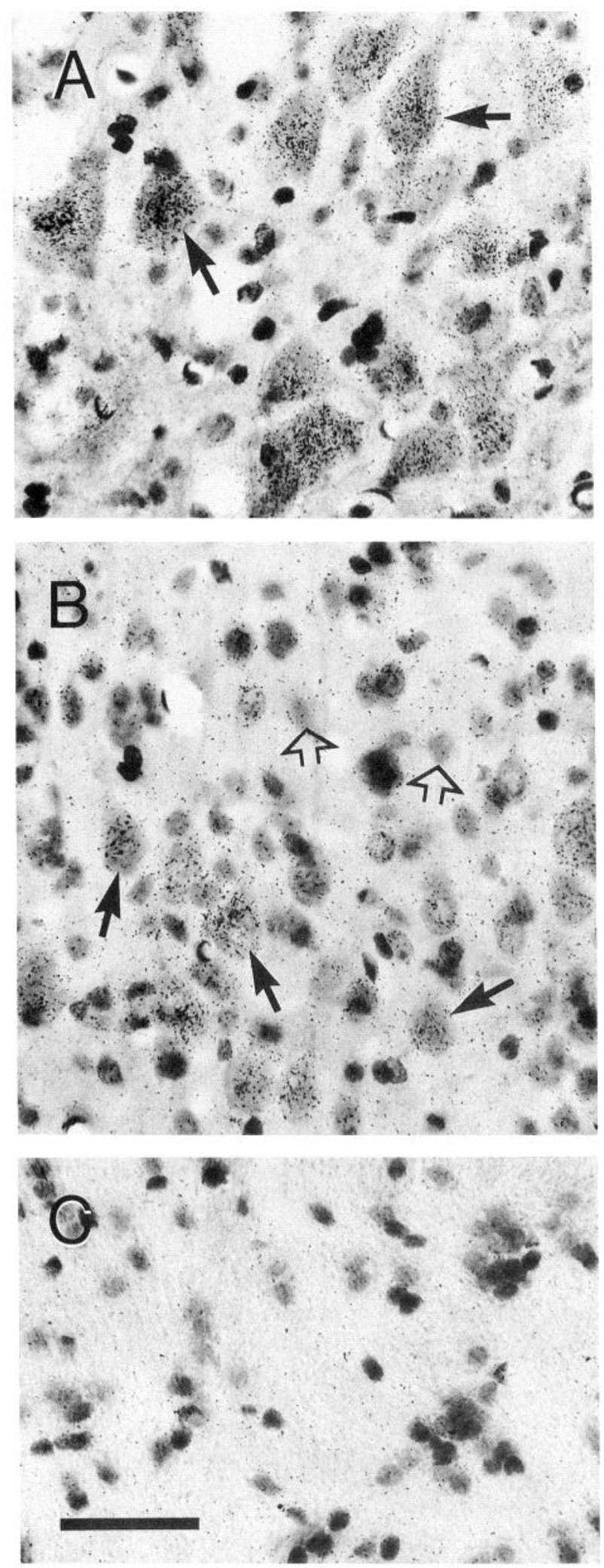

Figure 6. Agrin mRNA is expressed by neurons within the adult brain: high-magnification bright-field photomicrographs showing autoradiographic localization of agrin cRNA hybridization in motor neurons $(A)$, neocortex $(B)$, and a fiber tract $(C)$. In the facial motor nucleus $(A)$, large neurons are heavily labeled by autoradiographic grains (arrows). In layer $\mathrm{V}$ of the neocortex $(B)$, some neurons are heavily labeled (solid arrows) while others are associated with few autoradiographic grains (open arrows). In the medial lemniscus $(C)$, as in other major fiber tracts in the solitarious, which also contains cholinergic neurons, was labeled as well (Fig. 5D). In addition, heavily labeled neurons were scattered across the reticular formation (Fig. $5 B, D$ ) and the spinal trigeminal nucleus (Fig. $5 D$ ), whereas cells in the cochlear and vestibular nuclei (Fig. $5 C$ ) were only lightly labeled. Very low to background levels of hybridization were observed in the cell-dense inferior olivary complex (Fig. 5D).

\section{Cellular localization of agrin $m R N A$}

In general, the pattern of agrin cRNA hybridization suggested a predominant neuronal localization. Areas of hybridization corresponded with neuronal cytoarchitectonic fields, whereas no specific cellular labeling was observed in the major myelinated fiber tracts, including the anterior commissure (Fig. 4C), corpus callosum (Fig. $4 C$ ), cerebral peduncle (Fig. $4 F$ ), inferior cerebellar peduncle (Fig. $5 B$ ), and the facial nerve (Fig. $5 B$ ). Moreover, hybridization densities were generally low in areas of neuropil containing a greater number of glia, as opposed to neuronal cell bodies, such as cortical layer I and the hippocampal molecular layers (Fig. 4E). This pattern of hybridization would be consistent with a predominantly neuronal localization of agrin mRNA. To assess this hypothesis further, we examined tissue sections at high magnification stained with toluidine blue following development for emulsion autoradiography (Fig. 6). With the notable exception of the olfactory nerve, silver grain densities were greatest over neuronal perikarya. For example, consistent with expression of agrin mRNA by spinal motor neurons, dense clusters of grains were clearly visible over the large cell bodies of facial (Fig. 6A) and other motor neuron cell bodies in brainstem nuclei. Labeling was also observed over neurons throughout other regions of the brain, layer $\mathrm{V}$ neurons of the neocortex being a typical example (Fig. $6 B$ ). Neurons were identified in these fields based on their large size. By comparison, the density of autoradiographic grains over regions of gray matter lacking neuronal cell bodies and fiber tracts was similar to background (Fig. $6 B, C$ ).

\section{Agrin $m R N A$ expression is not restricted to cholinergic pathways}

The broad distribution of agrin mRNA in rat brain indicates that agrin gene expression is not restricted to cholinergic neurons. To examine the degree of correspondence between agrin expression and cholinergic and cholinoceptive neurons, the distributions of mRNAs encoding ChAT, the $\beta 2$ subunit of the neuronal nicotinic $\mathrm{AChR}$, and agrin were compared in adjacent tissue sections.

Previous studies have shown that a probe specific for ChAT mRNA labels neuron cell bodies located in well-characterized cholinergic nuclei (Lauterborn et al., 1993). Using this ChATspecific probe, several areas were observed to contain neurons expressing both ChAT and agrin mRNA, including the spinal motor neurons (Fig. 3) and the brainstem cholinergic neurons described above. However, regions were also identified that did not express ChAT mRNA but did express significant levels of agrin mRNA. For example, in the basal forebrain, agrin mRNA expression was localized to neurons within both the medial and lateral septum but was particularly low in the horizontal limb

adult brain, the density of autoradiographic grains was very low and similar to background. Scale bar, $50 \mu \mathrm{m}$. 

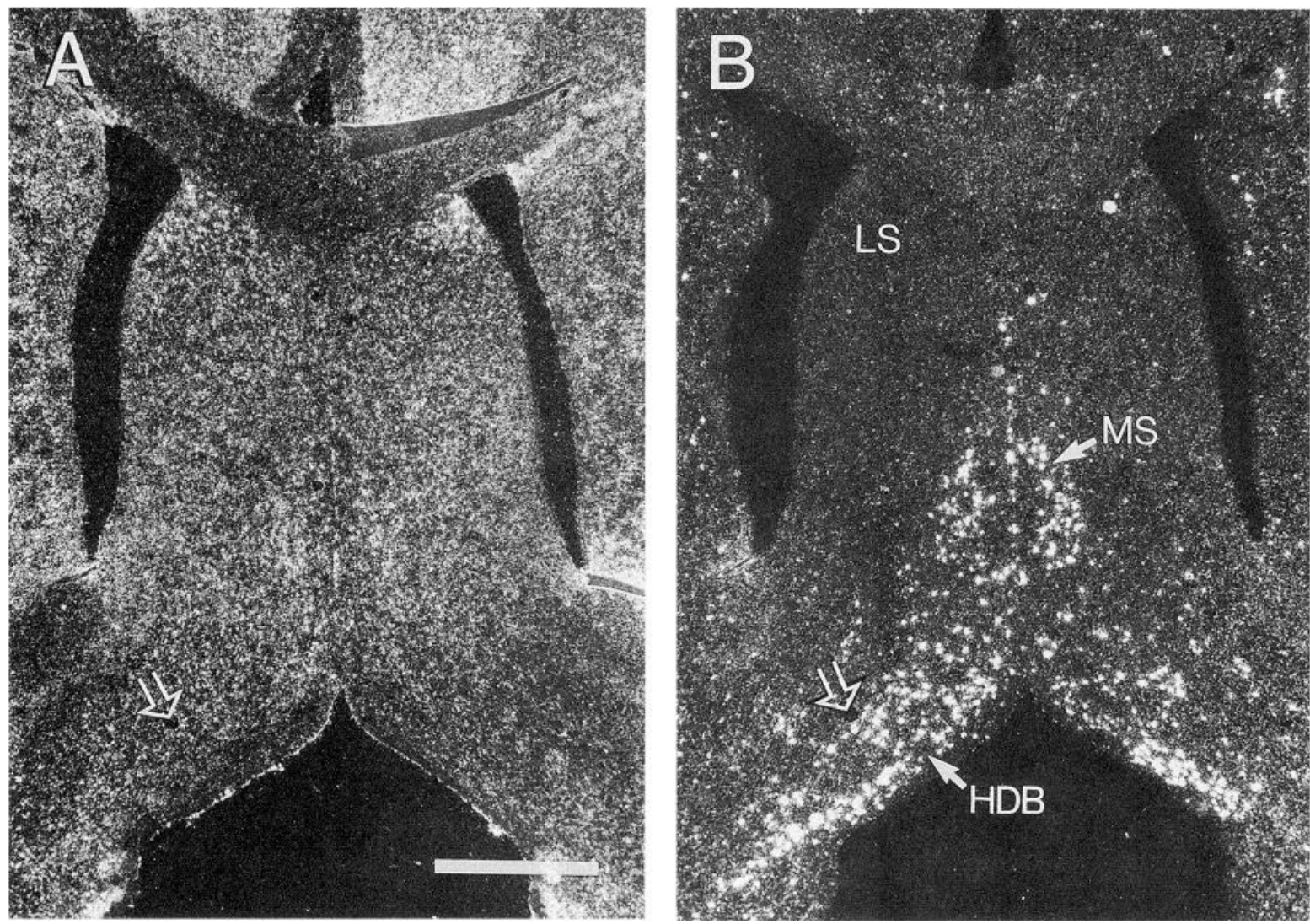

Figure 7. Expression of agrin mRNA is not restricted to cholinergic neurons: dark-field photomicrographs of adjacent coronal sections through the septum showing hybridization to cRNA probes of agrin $(A)$ and ChAT $(B)$. Prominent ChAT cRNA hybridization labels individual cells restricted to the medial septal nucleus $(M S)$ and the horizontal limb of the diagonal band $(H D B)$. In contrast, lower levels of agrin cRNA hybridization label medial as well as lateral septal regions $(L S)$. Open arrow indicates the same blood vessel in $A$ and $B$. Scale bar, $900 \mu \mathrm{m}$.

of the diagonal bands (Fig. $7 A$ ). In contrast, hybridization to the ChAT cRNA probe was dense and restricted to cells within both the medial septal nucleus and the diagonal bands (Fig. $7 B$ ). Similarly, the adult hippocampus lacks ChAT mRNA-positive neurons (Lauterborn et al., 1993; data not shown) yet the agrin cRNA probes hybridized strongly to neurons in both the granule and pyramidal cell layers (Fig. $8 C$ ).

The $\beta 2$ subunit is a reliable indicator of cells expressing nicotinic $A C h R$ in the adult rat brain since it is required for a functional neuronal nicotinic cholinergic receptor. As previously reported (Deneris et al., 1988; Wada et al., 1989), the cRNA for the $\beta 2$ subunit used in the present study labels cells broadly distributed across the CNS, reminiscent of the labeling pattern observed for agrin mRNA described above. However, differences between these patterns of hybridization were evident. For example, in the olfactory bulb the agrin cRNA densely labeled the internal granular, mitral, and olfactory nerve layers (Fig. $8 A$ ). The cRNA probe for $\beta 2$ also labeled the mitral cell layer but, in contrast, no hybridization was observed in either the granule cell or olfactory nerve layers (Fig. $8 B$ ). A similar lack of correspondence was evident in hippocampus. No agrin cRNA hybridization was evident in the pyramidal cells of hippocampal region $\mathrm{CA} 2$ (Fig. $8 C$ ), while the $\beta 2$ probe hybridized intensely to these neurons (Fig. $8 D$ ).

\section{Regional distribution of alternately spliced agrin $m R N A$}

In embryonic rat spinal cord, four agrin isoforms, agrin ${ }_{0}, \operatorname{agrin}_{8}$, agrin $_{11}$, and agrin $_{19}$, have been shown to result from alternative
RNA splicing events that occur at amino acid 1779 (Ferns et al., 1992). Expression studies have shown that each agrin isoform differs in its ability to induce aggregation of $\mathrm{AChR}$ on cultured myotubes (Ferns et al., 1992). The observation that agrin mRNA is broadly distributed throughout the CNS raised the question of whether the different isoforms might show region-specific patterns of expression. To determine the pattern of alternative agrin RNA splicing in the brain, RNA from different brain regions was subjected to two rounds of amplification by PCR using nested primers flanking amino acid 1779 of rat agrin.

PCR of cDNA synthesized from rat brain RNA resulted in amplification of four major products resolved by gel electrophoresis (Fig. 9A). Several lines of evidence indicate that these products correspond to amplification of $\operatorname{agrin}_{0}, \operatorname{agrin}_{8}, \operatorname{agrin}_{11}$, and agrin $_{19}$ mRNA. A high degree of specificity is inherent in PCR reactions using nested primer pairs, and each product could be clearly identified by its predicted molecular weight. Moreover, each PCR product exhibited a unique restriction map predicted by the published sequence for rat agrin (Ferns et al., 1992; Fig. 1). However, although all four alternatively spliced agrin mRNAs are present in the adult rat brain, their level of expression appears to vary from region to region (Fig. 9A). For example, $\operatorname{agrin}_{0}$, agrin $_{8}$, and agrin $_{19}$ were detected in RNA extracted from spinal cord and all regions of the brain analyzed. In contrast, agrin ${ }_{11}$ was present at detectable levels only in RNA isolated from forebrain regions including the olfactory bulb, septum/basal forebrain, caudate/putamen, hippocampus, neo- 

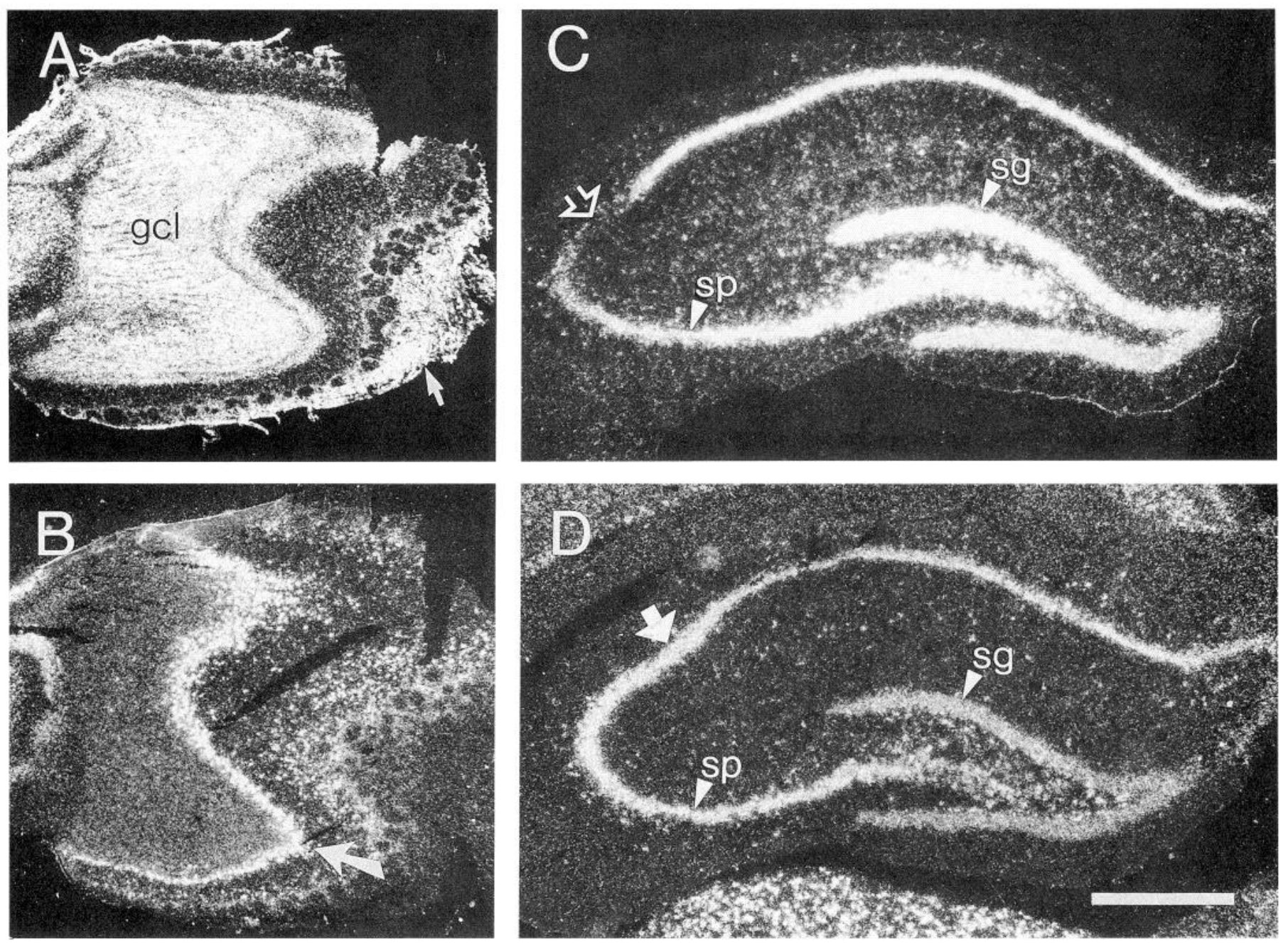

Figure 8. Expression of agrin mRNA is not restricted to cholinoreceptive neurons: dark-field photomicrographs of adjacent sections through olfactory bulb $(A, B)$ and hippocampus $(C, D)$ showing hybridization to agrin $(A, C)$ and $\beta 2$ nicotinic AChR $(B, D)$ cRNA probes. In the olfactory bulb, dense agrin cRNA labeling is seen in the internal granule cell $(\mathrm{gcl})$, mitral, and olfactory nerve $(A$, arrow) layers. In contrast, dense $\beta 2 \mathrm{cRNA}$ hybridization is seen only in the mitral cell layer $(B$, arrow). In hippocampus, the agrin cRNA labels stratum granulosum $(s g)$ and stratum pyramidale $(s p)$ of regions CA 3 and CA1. Region CA 2 is not labeled by the agrin cRNA ( $C$, open arrow). In contrast, $\beta 2$ cRNA $(D)$ labels stratum granulosum and stratum pyramidale throughout regions CA1-CA3; arrow indicates CA2. Scale bar, $1 \mathrm{~mm}$ for $A, 1.3 \mathrm{~mm}$ for $B, 650 \mu \mathrm{m}$ for $C$ and $D$.

cortex, and diencephalon, even following prolonged exposure of autoradiograms. The small difference in size and the fact that each transcript competes for the same pool of primers during first-strand cDNA synthesis and PCR amplification make it unlikely that the efficiency of DNA polymerization will differ significantly between each agrin isoform. Thus, differences in the proportions of the PCR products should provide an accurate representation of the relative abundance of agrin mRNAs in each brain region.

To compare regional differences in alternative agrin RNA splicing in more detail, we analyzed the relative levels of each transcript within individual regions by densitometry. High lev-

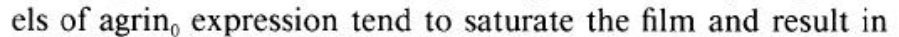
underestimation of this transcript and overestimation of the contribution of less abundant isoforms. To minimize this source of error, density measurements were obtained for the shortest autoradiographic exposures consistent with being able to identify all four transcripts unambiguously. The cumulative data from four separate experiments are summarized in Figure $9 B$. In addition to the observation that agrin $_{11}$ expression is restricted to forebrain regions, other differences in the pattern of al- ternative splicing were also apparent. For example, while agrin was the most abundant transcript (mean level for all regions, $49.1 \pm 2.4 \%$ SEM), significantly higher levels of agrin $n_{0}$ were expressed in olfactory bulb $(65.1 \pm 2.6 \% \mathrm{SEM} ; p<0.001)$, and cerebellum $(59.3 \pm 3.4 \% \mathrm{SEM} ; p<0.02)$. Levels of agrin 8 mRNA were relatively uniform throughout the brain (mean for all regions, $20.9 \pm 1.6 \%$ SEM) but significantly lower in the olfactory bulb $(9.3 \pm 1.2 \% \mathrm{SEM} ; p<0.02)$. Similar but more subtle trends in these data were also apparent in $\operatorname{agrin}_{19}$ expression, with highest levels in mesencephalon and lowest in olfactory bulb. Overall, our results suggested that each brain region was associated with a specific pattern of alternative splicing and level of expression of each agrin transcript.

\section{Discussion}

Agrin has been proposed as the neuronal agent that triggers accumulation of AChR at the neuromuscular junction during development (McMahan, 1990). Our results show that the agrin gene is widely expressed throughout the adult CNS and is not restricted to cholinergic neuronal systems. Further, we show that alternatively spliced transcripts of agrin, previously demonstrat- 
A

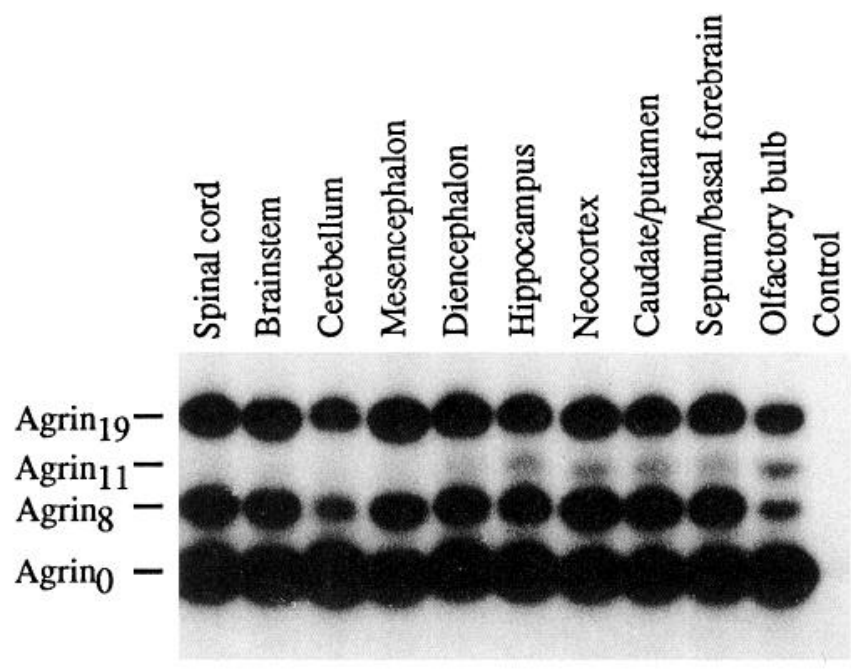

B

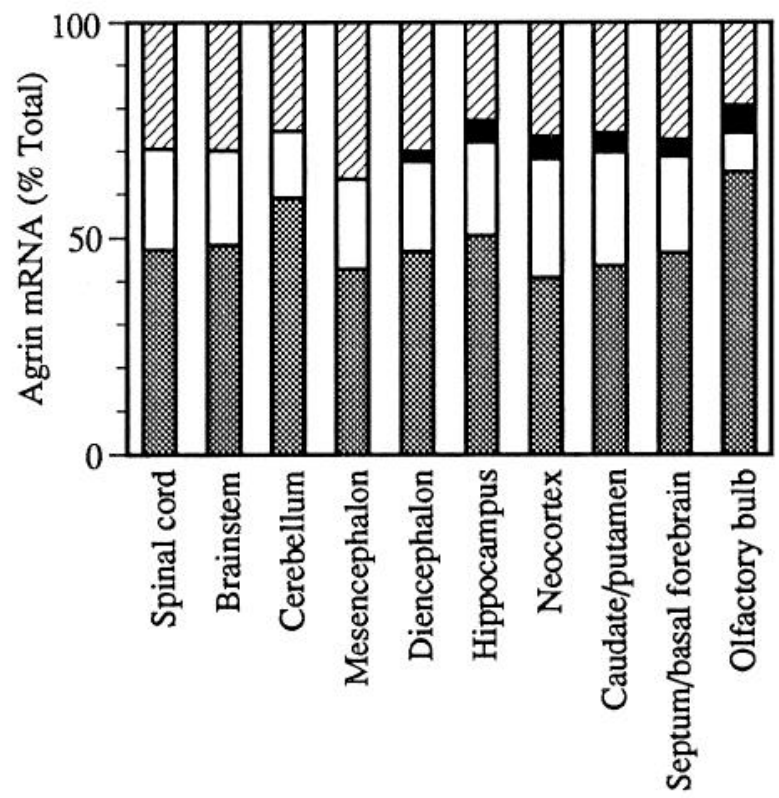

Figure 9. Alternatively spliced isoforms of agrin mRNA are expressed in the adult CNS. First-strand cDNA synthesized from RNA isolated from different regions of the rat CNS were subject to two rounds of amplification using nested primers flanking a point of alternative splicing in the rat agrin cDNA. $A$, Film autoradiogram from a typical experiment showing that each of the four agrin isoforms is expressed in the CNS. Note that one of these isoforms, agrin $_{11}$, can only be detected in RNA isolated from regions of the forebrain. The control lane represents a reaction in which RNA was omitted from first-strand cDNA synthesis. $B$, Expression levels of each transcript was calculated using quantitative densitometry of film autoradiograms and expressed as a fraction of all four transcripts. The histogram summarizes the results

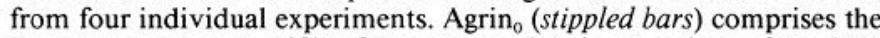
largest percentage ( $>40 \%$ ) of these transcripts in all regions of the CNS while agrin $_{19}$ (hatched bars) and agrin ${ }_{8}$ (open bars) account for the majority of the remaining $60 \%$. By comparison, when agrin (solid bars) $_{11}$ is expressed, it constitutes a very small percentage $(<7 \%)$ of these transcripts. ed to encode agrin proteins that have high activity in AChR aggregation assays (Campanelli et al., 1991; Ferns et al., 1992), are present in all major regions of the brain. Together, these results suggest that agrin plays a wider role in the nervous system than that originally proposed (McMahan, 1990).

In the present study, agrin mRNA expression, determined by in situ hybridization, was broadly associated with neuronal groups and conformed to identified cytoarchetectonic areas in the brain and spinal cord. Consistent with this observation, silver grains in tissue sections stained with toluidine blue were clearly associated with neuronal perikarya. In contrast, levels of hybridization in regions of neuropil predominantly populated by astroglial cells, such as layer I of the neocortex, were similar to background, as was also the case in regions of the white matter that would contain higher levels of oligodendroglia, such as the corpus callosum, cerebral peduncle, and white matter of the spinal cord. By virtue of their abundance, a significant fraction of all agrin mRNA in the brain might still be attributable to glial cells. However, the relative level of expression in glia versus neurons in the adult brain appears to be lower than in embryonic peripheral nerves and ganglia similarly visualized by in situ hybridization (Thomas et al., 1993). Taken together, the results of our in situ hybridization studies suggest that, in the adult CNS, agrin mRNA is expressed at highest concentration in neurons.

Anti-agrin antibodies label the basal lamina of blood vessel endothelia in the adult and embryonic CNS (Magill-Solc and McMahan, 1988) and agrin mRNA has been detected by in situ hybridization in the spinal artery and aorta in embryonic chick and rat (Rupp et al., 1991; Tsim et al., 1992). Although we did not look at blood vessels specifically, the apparent lack of labeling in blood vessels and capillaries throughout the in situ material suggests that agrin mRNA expression in endothelial cells in the adult CNS is at similarly low levels as in glia. Interestingly, in situ hybridization to sections through the electric lobe of Torpedo californica (Smith et al., 1992), a region of the CNS previously shown to contain intensely agrin immunoreactive capillaries (Magill-Solc and McMahan, 1988), also failed to detect hybridization to blood vessels, consistent with the possibility that agrin expression in endothelial cells may decline during development. Although below the level of detection by in situ hybridization, agrin mRNA levels in adult endothelial cells may, nevertheless, be sufficient to maintain the intense agrin immunoreactivity associated with blood vessel endothelia, or alternatively, agrin may derive from other cellular sources such as astrocyte end-foot processes that impinge upon them. Additional experiments using more sensitive techniques will be required to determine the levels of agrin mRNA expression in endothelial cells and the cellular origin of agrin protein associated with them.

Labeling in the olfactory nerve layer was unique among regions analyzed because this was the one area in which hybridization was clearly not associated with neuronal cell bodies. The intense labeling of the olfactory nerve layer demonstrates that specific populations of non-neuronal cells in the CNS can express agrin. The olfactory nerve layer contains centrally derived astroglia as well as fibroblasts and peripherally derived ensheathing cells but no neuronal cell bodies (Doucette, 1990). The astroglial cells are preferentially distributed within the deeper aspects of the olfactory nerve layer (Bailey and Shipley, 1993) and thus most probably do not account for the agrin cRNA hybridization that was evenly distributed across the lamina. Agrin expression by ensheathing cells is more likely. The ensheathing cells derive 
from precursor cells from the olfactory epithelium in the nasal cavity (Chuah and Au, 1991) and are distributed throughout the course of the olfactory nerve excepting the intraglomerular terminal arbors. These glial-type cells express both glial fibrillary acidic protein and $\mathrm{S} 100$ (Chuah and $\mathrm{Au}, 1993$ ) but are morphologically distinct from central astroglia (Doucette, 1990). In addition to agrin, the adhesion molecules laminin (Liesi, 1985), L1, N-CAM, and E-N-CAM (Miragall et al., 1988, 1989) are continuously expressed in the olfactory nerve, possibly related to the ongoing turnover and replacement of olfactory neurons that continue to grow axons into this region throughout adulthood. Thus, expression of agrin in the olfactory nerve may be related to the unique degree of plasticity associated with this structure in the adult.

Agrin has been shown to be expressed by motor neurons in spinal cord (Rupp et al., 1991; Smith et al., 1992; Tsim et al., 1992) and autonomic ganglia (Thomas et al., 1993). Our own observations extend these findings by demonstrating that the agrin gene is also expressed in all of the cholinergic cell groups that give rise to the efferent cranial nerves (e.g., the facial, hypoglossal, solitary, and ambiguus nuclei). However, agrin expression in brain was not limited to, or reliably associated with, cholinergic neurons. Hybridization to agrin mRNA labeled the cholinergic medial septal nucleus, whereas there were particularly low levels of hybridization in the cholinergic horizontal limb of the diagonal band. Moreover, agrin mRNA was expressed at particularly high levels by neurons in the olfactory bulb and hippocampus, regions previously shown (Lauterborn et al., 1993), and confirmed in the present study, to lack ChAT mRNA. Our findings also indicate that agrin expression is not restricted to cholinoceptive neurons in the brain. Using a probe against the $\beta 2$ neuronal nicotinic receptor subunit, brain regions were identified that contained cholinoceptive ncurons but did not express agrin mRNA (e.g., CA2 of hippocampus). Other regions were found to express high levels of agrin mRNA but no $\beta 2$ receptor mRNA (e.g., granule cells of olfactory bulb). Thus, the distribution of agrin mRNA indicates that, in addition to cholinergic and cholinoceptive neurons, neurons involved in other neurotransmitter pathways are likely to express agrin as well.

Alternative RNA splicing generates four distinct agrin mRNA isoforms, agrin $0, \operatorname{agrin}_{8}$, agrin 11 , and agrin 19 , that have been shown to be active in AChR aggregating assays using rat myotubes (Ferns et al., 1992). We demonstrate here that each of these agrin mRNAs is widely expressed in the brain, raising the issue of the cellular origin of each transcript. It has recently been reported that RNA isolated from chick embryo optic nerve, a CNS axonal system that contains glial cells but no neurons, contains only agrin ${\text { while both } \text { agrin }_{0} \text { and agrin }}_{11}$ were detected in RNA isolated from retina (McMahan et al., 1992). Similarly, peripheral nerves contain only agrin ${ }_{0}$, while cells from the spinal cord contain $\operatorname{agrin}_{0}$, agrin $_{11}$, and $\operatorname{agrin}_{19}$ (McMahan et al., 1992). These results suggest that non-neuronal cells in the nervous system synthesize only agrin isoforms that lack both the 8 and 11 amino acid exons. Recently, the cellular origin of different transcripts has been addressed directly by using single-cell PCR to determine the agrin mRNA profile of identified cells in chick ciliary and dorsal root ganglia (Smith et al., 1993; Smith, personal communication). These studies demonstrate that while non-neuronal cells express only agrin a $_{0}$, neurons express various combinations of one or more agrin mRNAs that may include $\operatorname{agrin}_{0}$. Thus, the simplest interpretation of our results is that agrin $_{8}$, agrin ${ }_{11}$, and agrin ${ }_{19}$ are expressed by neurons. Moreover, while we cannot ascertain the possible level of the contribution to agrin by glial cells, some agrin $_{0}$ mRNA in adult brain is likely to be of neuronal origin as well.

Both the levels of expression and pattern of alternative agrin RNA splicing in the chick ciliary ganglion have been shown to be regulated during development (Thomas et al., 1993). We show here that different regions of adult brain exhibit characteristic expression levels and patterns of alternative splicing of agrin RNA. For example, within the densely packed pyramidal cell layer of hippocampus, agrin mRNA was present at high levels in regions CA3 and CA 1 but barely detectable in region CA2. Similarly, in contrast to the superficial cells of the olfactory tubercle, the underlying densely packed neuronal clusters of the islands of Calleja were not labeled by the agrin probe. Each brain region examined also exhibited a characteristic pattern of alternative agrin RNA splicing; most notably, the agrin $_{11}$ transcript was restricted to forebrain structures. At what stage in development the pattern of alternative splicing seen in the adult first appears remains to be determined. However, our results demonstrate that agrin gene expression must be influenced by regionally specific cues in the adult CNS. These observations add further support to the idea that alternative splicing represents a physiologically significant mechanism whereby agrin activity may be regulated.

Previous studies have shown that extracts of embryonic and adult brains contain AChR aggregating activity that can be precipitated by anti-agrin antibodies (Godfrey et al., 1988; MagillSolc and McMahan, 1988). Consistent with this observation, we find that all four agrin isoforms active in AChR clustering assays are widely expressed in the brain. What function might agrin serve in the brain? Receptors for neurotransmitters and other protcins are clustered at the postsynaptic membranes of neuron-neuron synapses, and extracellular material is present in the synaptic cleft (Jessell and Kandel, 1993). If agrin plays a role at neuronal synapses similar to that proposed at the neuromuscular junction, our data suggest that this activity is not restricted to nicotinic synapses. Agrin's similarity to other extracellular matrix molecules and the recent suggestion that agrin may play a role in the mobilization of neurotrophic factors in the CNS (Patthy and Nikolics, 1993) raise the possibility that agrin exerts a more generalized influence over neuronal behavior in many regions of the CNS.

\section{References}

Bailey MS, Shipley MT (1993) Astrocyte subtypes in the rat olfactory bulb: morphological heterogeneity and differential laminar distribution. J Comp Neurol 328:501-526.

Campanelli JT, Hoch W, Rupp F, Kreiner T, Scheller RH (1991) Agrin mediates cell contact-induced acetylcholine receptor clustering. Cell 67:909-916.

Chomczynski P, Sacchi N (1987) Single-step method of RNA isolation by acid guanidinium thiocyanate-phenol-chloroform extraction. Anal Biochem 162:156-159.

Chuah MI, Au C (1991) Olfactory Schwann cells are derived from precursor cells in the olfactory epithelium. J Neurosci Res 29:172180.

Danielson PE, Forss-Petter S, Brow MA, Calavetta L, Douglass J, Milner RJ, Sutcliffe JG (1988) p1B15: a cDNA clone of the rat mRNA encoding cyclophilin. DNA 7:261-267.

Deneris ES, Conolly J, Boulter J, Wada E, Wada K, Swanson LW, Patrick J, Heinemann S (1988) Primary structure and expression of $\beta 2$ : a novel subunit of neuronal nicotinic acetylcholine receptors. Neuron 1:45-54. 
Doucette R (1990) Glial influences on axonal growth in the primary olfactory system. Glia 3:433-449.

Feinberg AP, Vogelstein B (1983) A technique for radiolabeling DNA restriction endonuclease fragments to high specific activity. Anal Biochem 132:6-13.

Ferns M, Hoch W, Campinelli JT, Rupp F, Hall ZW, Scheller RH (1992) RNA splicing regulates agrin-mediated acetylcholine receptor clustering activity on cultured myotubes. Neuron 8:1079-1086.

Gall CM, Isackson PJ (1989) Limbic seizures increase neuronal production of messenger RNA for nerve growth factor. Science 245:758761 .

Godfrey EW, Dietz ME, Morstad AL, Wallskog PA, Yorde DE (1988) Acetylcholine receptor-aggregating proteins are associated with the extracellular matrix of many tissues in Torpedo. J Cell Biol 106:12631272.

Hall ZW, Sanes JR (1993) Synaptic structure and development: the neuromuscular junction. Neuron [Suppl] 10:99-121.

Jessell TM, Kandel ER (1993) Synaptic transmission: a bidirectional and self-modifiable form of cell-cell communication. Neuron [Suppl] 10:1-30.

Kawasaki ES (1990) Amplification of RNA. In: PCR protocols: a guide to methods and applications, pp 21-27. San Diego: Academic.

Lauterborn JC, Isackson PJ, Gall CM (1991) Nerve growth factor mRNA-containing cells are distributed within regions of cholinergic neurons in the rat basal forebrain. J Comp Neurol 306:439-446.

Lautcrborn JC, Isackson PJ, Montalvo R, Gall CM (1993) In situ hybridization of choline acetyltransferase mRNA in adult rat brain and spinal cord. Mol Brain Res 17:59-69.

Liesi $\mathbf{P}$ (1985) Laminin immunoreactive glia distinguish regenerative adult CNS systems from non-regenerative ones. EMBO J 4:25052511.

Magill-Solc C, McMahan UJ (1988) Motor neurons contain agrin-like molecules. J Cell Biol 107:1825-1833.

McMahan UJ (1990) The agrin hypothesis. Cold Spring Harbor Symp Quant Biol 55:407-418.

McMahan UJ, Horton SE, Werle MJ, Honig LS, Kröger S, Ruegg MA, Escher G (1992) Agrin isoforms and their role in synaptogenesis. Curr Opin Cell Biol 4:869-874.
Miragall F, Kadmon G, Husmann M, Schachner M (1988) Expression of cell adhesion molecules in the olfactory system of the adult mouse: presence of the embryonic form of N-CAM. Dev Biol 129:516-531.

Miragall F, Kadmon G, Schachner M (1989) Expression of Ll and $\mathrm{N}-\mathrm{CAM}$ cell adhesion molecules during development of the mouse olfactory system. Dev Biol 135:272-286.

Milner RJ, Sutcliffe JG (1983) Gene expression in rat brain. Nucl Acids Res 11:5497-5520.

Nastuk MA, Fallon JR (1993) Agrin and the molecular choreography of synapse formation. Trends Neurosci 16:72-76.

Patthy L, Nikolics K (1993) Functions of agrin and agrin-related protcins. Trends Ncurosci 16:76-81.

Reichardt LF, Tomaselli KJ (1991) Extracellular matrix molecules and their receptors: functions in neural development. Annu Rev Neurosci 14:531-570.

Ruegg MA, Tsim KWK, Horton SE, Kröger S, McMahan UJ (1992) The agrin gene codes for a family of basal lamina proteins that differ in function and distribution. Neuron 8:691-699.

Rupp F, Payan DG, Magill-Solc C, Cowan DM, Scheller RH (1991) Structure and expression of a rat agrin. Neuron 6:811-823.

Sambrook JM, Fritsch EF, Maniatis T (1989) Molecular cloning: a laboratory manual. Cold Spring Harbor, NY: Cold Spring Harbor Laboratory.

Smith MA, Magill-Solc C, Rupp F, Yao Y-MM, Schilling JW, Snow P, McMahan UJ (1992) Isolation and characterization of an agrin homolog in the marine ray. Mol Cell Neurosci 3:406-417.

Smith MA, Tran C, O'Dowd DK (1993) Single neurons express multiple agrin mRNA isoforms. Soc Neurosci Abstr 19:1295.

Thomas WS, O'Dowd DK, Smith MA (1993) Developmental expression and alternative splicing of chick agrin RNA. Dev Biol 158: 523-535.

Tsim KWK, Ruegg MA, Escher G, Kröger S, McMahan UJ (1992) cDNA that encodes active agrin. Neuron 8:677-689.

Wada E, Wada K, Boulter J, Deneris E, Heinemannn S, Patrick J, Swanson LW (1989) Distribution of alpha2, alpha3, alpha4, and beta2 neuronal nicotinic receptor subunit mRNAs in the central nervous system: a hybridization histochemical study in the rat. J Comp Neurol 284:314-335. 